\title{
Modic Type 1 Changes: Detection Performance of Fat-Suppressed Fluid-Sensitive MRI Sequences
}

\section{Modic-Typ-1-Endplattenveränderungen: Detektionsrate mittels fettgesättigten, flüssigkeitssensitiven MRT- Sequenzen}

Authors

Tim Finkenstaedt ${ }^{1}$, Filippo Del Grande ${ }^{2}$, Nicolae Bolog ${ }^{3}$, Nils Ulrich ${ }^{4}$, Sina Tok $^{4}$, Orpheus Kolokythas ${ }^{5}$, Johann Steurer ${ }^{6}$, Gustav Andreisek ${ }^{1}$, Sebastian Winklhofer ${ }^{1,7}$, on behalf of the LSOS Study Group

\section{Affiliations}

1 Institute of Diagnostic and Interventional Radiology, University Hospital Zurich, University of Zurich, Zurich, Switzerland

2 Institute of Diagnostic and Interventional Radiology, Ospedale Regionale di Lugano, Lugano, Switzerland

3 Phoenix Diagnostic Clinic, Bucharest, Romania

4 Department of Neurosurgery, Spine Center, Schulthess Clinic, Zurich, Switzerland

5 Institute for Radiology and Nuclear Medicine, Kantonsspital Winterthur, Winterthur, Switzerland

6 Horten Center for patient oriented research and knowledge transfer, University Hospital Zurich, Zurich, Switzerland

7 Department of Neuroradiology, University Hospital Zurich, University of Zurich, Zurich, Switzerland

Key words

modic, magnetic resonance imaging, spinal canal, bone diseases, sensitivity and specificity

received 06.04 .2017

accepted 25.07.2017

\section{Bibliography}

DOI https://doi.org/10.1055/s-0043-118130

Published online: 27.11.2017

Fortschr Röntgenstr 2018; 190: 152-160

(c) Georg Thieme Verlag KG, Stuttgart · New York

ISSN 1438-9029

\section{Correspondence}

Sebastian Winklhofer, MD

Department of Neuroradiology, University Hospital Zurich, Frauenklinikstrasse 10, $\mathrm{CH}-8091$ Zurich

Tel.: ++41/44/2555600

Fax: $++41 / 44 / 2554504$

sebastian.winklhofer@usz.ch

\section{ZUSAMMENFASSUNG}

Ziel Ziel der Studie ist es, die Detektionsrate von Modic-Typ1-Endplattenveränderungen mittels fettgesättigten, flüssig- keitssensitiven MRT-Sequenzen gegenüber Standard T1- und T2-gewichteten Sequenzen an der Lendenwirbelsäule zu vergleichen.

Material und Methoden Sagittale T1, T2 und fettgesättigte, flüssigkeitssensitive MRT-Sequenzen von 100 Patienten (gesamt 500 Wirbelsegmente; 52 weiblich, Durchschnittsalter 74 \pm 7,4 Jahre; 48 männlich, Durchschnittsalter $71 \pm 6,3$ Jahre) wurden retrospektiv untersucht. Das Vorhandensein (ja/nein) und die Ausdehnung (Likert-skalierte Höhen-, Volumen- und anteroposteriore Endplattenausdehnung) von Modic-1-Veränderungen auf T1/T2 gegenüber fettgesättigten, flüssigkeitssensitiven MRT-Sequenzen wurden analysiert (McNemar/Wilcoxon-signed-rank test).

Ergebnisse Mittels fettgesättigter, flüssigkeitssensitiver MRT-Sequenzen konnten signifikant mehr Modic-1-Veränderungen detektiert werden als mittels T1-/T2-Sequenzen (156 vs. 93 Segmente; $p<0,001$ ). Die Ausdehnung von Modic-1-Veränderungen auf fettgesättigten, flüssigkeitssensitiven MRT-Sequenzen war signifikant größer gegenüber T1-/T2-Sequenzen (Höhe: 2,53 $\pm 0,82$ vs. 2,27 $\pm 0,79$, Volumen: $2,35 \pm 0,76$ vs. $2,1 \pm 0,65$, Endplattenausdehnung: $2,46 \pm 0,76$ vs. $2,19 \pm 0,81)$, $(p<0,05)$. Modic-1-Veränderungen, die nur auf fettgesättigten, flüssigkeitssensitiven Sequenzen, aber nicht auf T1-/T2-Sequenzen detektiert werden konnten, waren signifikant kleiner im Vergleich zu Modic-1Veränderungen, die auch auf T1-/T2-Sequenzen sichtbar waren $(p<0,05)$.

Schlussfolgerung Fettgesättigte, flüssigkeitssensitive Sequenzen haben nicht nur signifikant häufiger Modic-1-Veränderungen, sondern auch eine größere Ausdehnung ebendieser gegenüber Standard T1-/T2-Sequenzen nachweisen können.

\section{Kernaussagen:}

- Als die Modic-Klassifikation 1988 definiert wurde, waren T2-Sequenzen technisch bedingt nahezu fettgesättigt

- Fettsignal aktueller T2-Sequenzen ist deutlich heller, wodurch zusätzliches Knochenmarksödem maskiert werden kann

- Die ursprüngliche Definition von Modic-1-Veränderungen ist daher heutzutage nicht mehr zutreffend 
- Fettgesättigte, flüssigkeitssensitive Sequenzen haben häufiger/größere Ausdehnung von Modic-1-Veränderungen gegenüber T1-/T2-Sequenzen nachweisen können

\section{ABSTRACT}

Purpose To assess the performance of fat-suppressed fluidsensitive MRI sequences compared to T1-weighted (T1w) / T2w sequences for the detection of Modic 1 end-plate changes on lumbar spine MRI.

Materials and Methods Sagittal T1w, T2w, and fat-suppressed fluid-sensitive MRI images of 100 consecutive patients (consequently 500 vertebral segments; 52 female, mean age $74 \pm 7.4$ years; 48 male, mean age $71 \pm 6.3$ years) were retrospectively evaluated. We recorded the presence (yes/no) and extension (i. e., Likert-scale of height, volume, and end-plate extension) of Modic I changes in T1w/T2w sequences and compared the results to fat-suppressed fluid-sensitive sequences (McNemar/Wilcoxon-signed-rank test).

Results Fat-suppressed fluid-sensitive sequences revealed significantly more Modic I changes compared to T1w/T2w sequences (156 vs. 93 segments, respectively; $p<0.001$ ). The extension of Modic I changes in fat-suppressed fluidsensitive sequences was significantly larger compared to T1w/T2w sequences (height: $2.53 \pm 0.82$ vs. $2.27 \pm 0.79$, volume: $2.35 \pm 0.76$ vs. $2.1 \pm 0.65$, end-plate: $2.46 \pm 0.76$ vs.
$2.19 \pm 0.81),(p<0.05)$. Modic I changes that were only visible in fat-suppressed fluid-sensitive sequences but not in T1w/ T2w sequences were significantly smaller compared to Modic I changes that were also visible in T1w/T2w sequences $(p<0.05)$. Conclusion In conclusion, fat-suppressed fluid-sensitive MRI sequences revealed significantly more Modic I end-plate changes and demonstrated a greater extent compared to standard T1w/T2w imaging.

\section{Key Points}

- When the Modic classification was defined in 1988, T2w sequences were heavily $\mathrm{T} 2$-weighted and thus virtually fatsuppressed.

- Nowadays, the bright fat signal in T2w images masks edema-like changes.

- The conventional definition of Modic I changes is not fully applicable anymore.

- Fat-suppressed fluid-sensitive MRI sequences revealed more/greater extent of Modic I changes.

\section{Citation Format}

- Finkenstaedt T, Del Grande F, Bolog N et al. Modic Type 1 Changes: Detection Performance of Fat-Suppressed FluidSensitive MRI Sequences. Fortschr Röntgenstr 2018; 190: 152-160

\section{Introduction}

Lower back pain (LBP) is a musculoskeletal condition with an estimated lifetime risk of $60-80 \%$ that features a vast socio-economic impact with an estimated annual cost of $\$ 100-200$ billion for direct medical expenditures and loss of work productivity [1, 2]. A definitive underlying pathology of the spine or its associated soft tissues can be identified only in a small percentage of patients (approx. $20 \%$ ) with chronic lower back pain [3, 4]. However, one frequent reason for back pain is vertebral end-plate changes which are commonly classified on magnetic resonance imaging (MRI) according to Modic et al. [5] as Modic type I-III [6]. Modic I changes were seen more frequently in patients with acute LBP (46-60\%) compared to the asymptomatic general population $(6-20 \%)$ and are thus considered an independent cause of pain [3, 7 -13]. Among the different types of Modic end-plate changes, Modic I changes are most strongly associated with pain $[11,14,15]$. Several possible mechanisms in the pathogenesis of Modic I changes are discussed in the literature: with mechanical stress [16-20] and an underlying low virulent infection $[21,22]$ being most likely.

The formal classification provided by Modic et al. in 1988 defined Modic I changes as an edema-like signal intensity with a decreased signal intensity on T1-weighted (T1w) spin-echo images and a corresponding increased signal intensity on T2-weighted (T2w) images of the bone marrow adjacent to the end-plates. However, the non-fat-saturated T2w sequences used in 1988 on older MRI scanners were heavily T2-weighted with consecutive suppression of large amounts of fat signal and were thus virtually fat-suppressed and inherently edema-sensitive ( $>$ Fig. 1). Nowadays, in contrast, standard T2w sequences feature a bright fat signal and thus are usually not edema-sensitive. Thus, the way Modic changes were defined historically is no longer fully applicable and an adapted definition of Modic I changes might be required. For our study, we equated an end-plate-related increase in fluid signal on fat-suppressed fluid-sensitive sequences with Modic I changes.

Today, even if not yet established in the international guidelines [23], fat-suppressed fluid-sensitive sequences should be an integral part of routine MRI protocols in lumbar spinal imaging and are acquired in an increasing number of departments. Therefore, the purpose of this study was to assess the performance of fat-suppressed fluid-sensitive MRI sequences compared to T1w/ T2w sequences for the detection of Modic 1 end-plate changes on lumbar spine MRI.

\section{Materials and Methods}

This study was approved by the local ethics committee (blinded for review) and conducted in compliance with the Declaration of Helsinki. All patients received written and oral information about the study and gave their written informed consent for participation. 

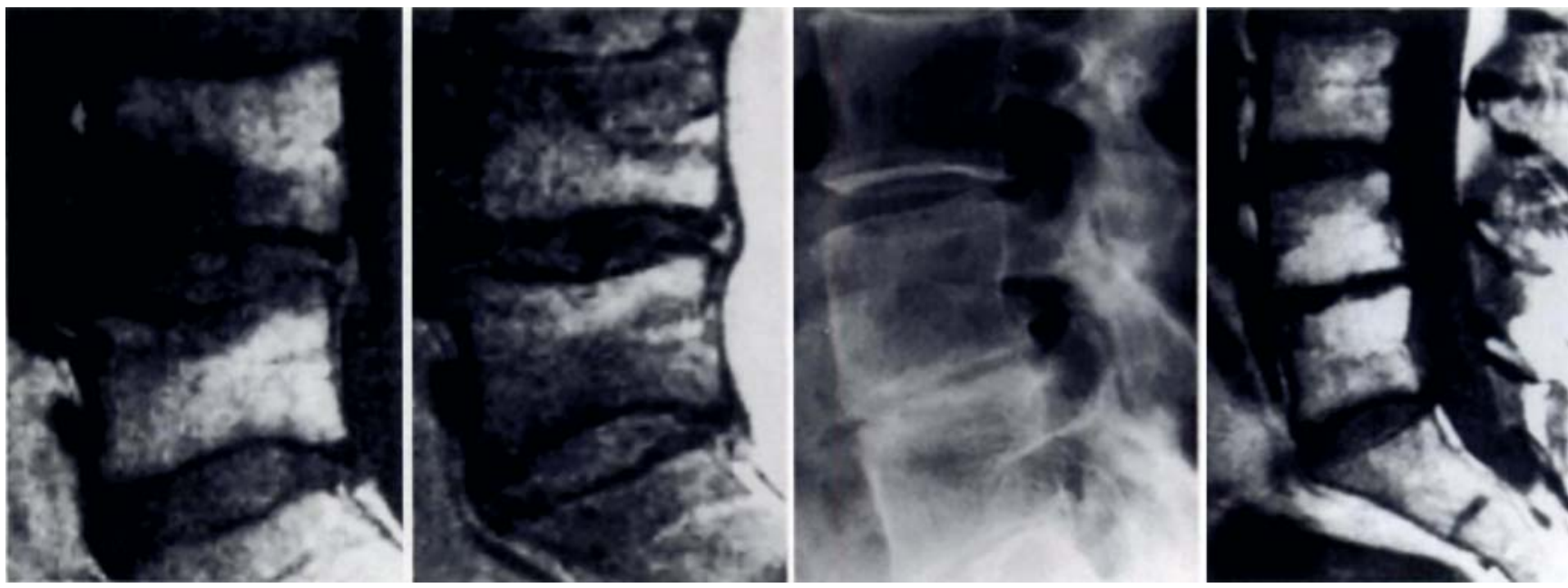

- Fig. 1 Image from the original publication of Modic et al. [5]. Modic I changes at level L4/5 in a 46-year-old man with low back pain. a T1w: Sagittal midline 500/ 17 (TR msec/TE msec), 4-mm-thick image of the lower lumbar spine. There is decreased T1w-signal intensity of the inferior aspect of L4 as well as the superior aspect of L5. b T2w: Sagittal midline 2000/90, 4-mm-thick image. There is increased T2w-signal of the adjacent portions of the L4 and L5 vertebral bodies and inherently suppression of most of the fat signal in the bone marrow. This results in a higher conspicuity of the edema-like Modic I changes (images by courtesy of Dr. Michael T. Modic).

- Abb. 1 Bilder aus der Originalpublikation von Modic et al. [5]. Modic-Typ-1-Veränderungen auf Höhe des Segments L4/5 bei einem 46-jährigen Mann mit lumbalen Rückenschmerzen. a T1: Sagittale Mittellinie der unteren Lendenwirbelsäule 500/17 (TR msec/TE msec), 4 mm Schichtdicke. Sichtbar ist ein erniedrigtes T1-Signal im inferioren Aspekt von L4 sowie superioren Aspekt von L5. b T2: Sagittale Mittellinie 2000/90, 4 mm Schichtdicke. Auffällig ist ein erhöhtes T2-Signal in den angrenzenden Anteilen von Wirbelkörper L4 und L5, während nahezu das gesamte Fettsignal des Knochenmarks unterdrückt ist. Diese technische Eigenart der damaligen T2-Sequenzen führt zu einer besseren Sichtbarkeit der ödemäquivalenten Modic-1-Veränderungen.

\section{Study population}

We evaluated $100 \mathrm{MRI}$ examinations of the lumbar spine (first lumbar vertebral body to first sacral vertebral body) of 100 patients ( 52 female, mean age $74 \pm 7.4$ years, range $50-87$ years; 48 male, mean age $71 \pm 6.3$ years, range $52-83$ years) with a resulting total of 500 vertebral segments.

All patients were participants of a much larger multicenter study, the so-called lumbar spinal canal stenosis outcome study (LSOS), and were prospectively and consecutively included between 2014 and 2015 at one of the ten participating centers (names blinded for review) [24]. All included patients had (a) clinical symptoms for LSS and were (b) $>50$ years old ( $\bullet$ Fig. 2 ). Additional inclusion criteria to the previously described basic criteria of LSOS were: (c) absence of prior lumbar spine surgery and (d) availability of sagittal T1w and T2w sequences as well as sagittal fatsuppressed fluid-sensitive MRI sequences (either Short-Tau Inversion Recovery (STIR), Spectral Presaturation with Inversion Recovery (SPIR), Spectral Attenuated Inversion Recovery (SPAIR), FatSat, Dixon, or Turbo-Inversion Recovery-Magnitude (TIRM)).

Thus, the LSOS database was searched for all of these inclusion criteria and 100 consecutive patients were selected for this retrospective analysis. The maximum time interval between the day of inclusion and MR imaging was 12 weeks.

\section{Imaging}

Due to the nature of a multicenter study with numerous participating institutions, imaging was performed on different MRI scanners at ten different radiology departments using field strengths

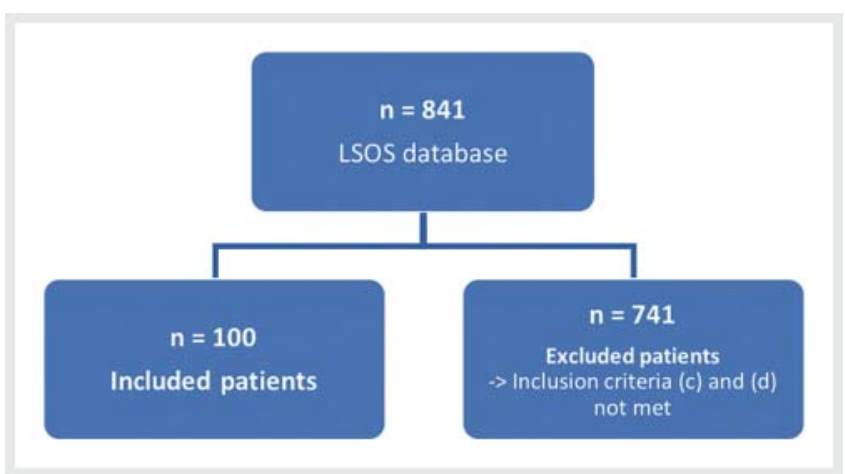

- Fig. 2 Flowchart of the study.

Abb. 2 Studien-Flussdiagramm.

of 1.5 and 3.0 Tesla and with varying scanning parameters. All scans were performed with the routinely used MRI protocols for patients with known or suspected lumbar spinal canal stenosis. The analyzed fat-suppressed fluid-sensitive MRI sequences included: STIR ( $n=50$ cases (50\%) equal 250 segments), SPIR ( $n=18$ cases ( $18 \%$ ) equal 90 segments), TIRM ( $n=18$ cases ( $18 \%$ ) equal $n=90$ segments), Fat-Sat ( $n=5$ cases ( $5 \%$ ) equal 25 segments), Dixon ( $n=5$ equal ( $5 \%) 25$ segments), SPAIR ( $n=4$ cases $(4 \%)$ equal 20 segments). In the majority of cases, the image matrix for fat-suppressed fluid-sensitive MRI sequences was 256x256 and less frequently a matrix of $512 \times 512$ was used. All imaging data were collected and stored in the picture archiving and com- 

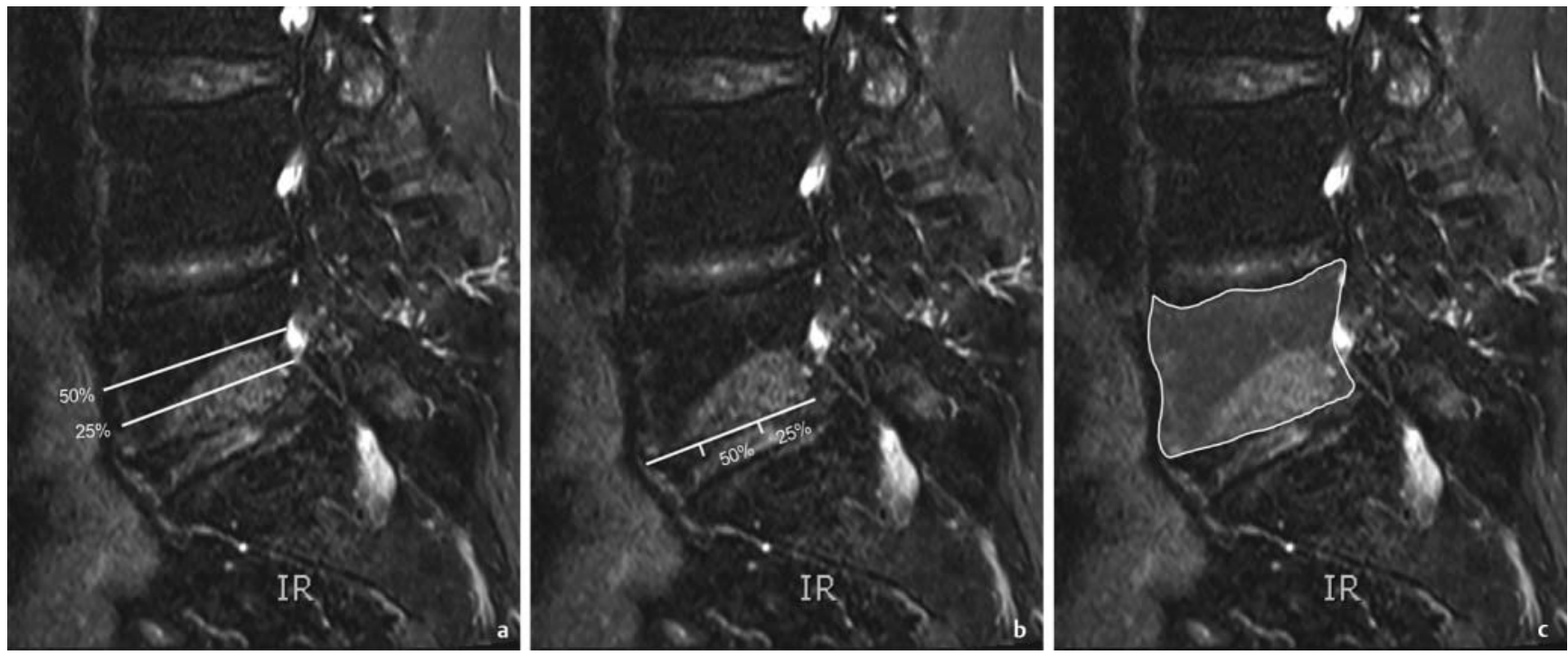

Fig. 3 Sagittal MRI sequence (STIR) of a 59-year-old male patient depicts the three parameters used to quantify the extension of Modic I changes: a maximum height (craniocaudally) affected by Modic changes: between $25 \%$ and $50 \%$ of the vertebral body; $\mathbf{b}$ maximum volume of Modic I changes in relation to the entire vertebral body: between $25 \%$ and $50 \%$ of the vertebral body; c end-plate extension of Modic changes in the anteroposterior direction: $>50 \%$ of the end-plate.

- Abb. 3 Sagittale MRT-Sequenz (STIR) eines 59-jährigen Patienten zeigt exemplarisch die drei angewendeten Parameter zur Messung der Ausdehnung der Modic-1-Veränderungen: a maximale Höhe (kraniokaudal) betroffen von den Modic-Veränderungen: $25 \%$ bis 50 \% des Wirbelkörpers; b maximales Volumen der Modic-1-Veränderungen in Bezug auf den gesamten Wirbelkörper: $25 \%$ bis $50 \%$ des Wirbelkörpers; c Endplattenausdehnung der Modic-Veränderungen in anteroposteriorer Ausdehnung: > 50 \% der Endplatte.

munication system (PACS) (IMPAX 6; AGFA Healthcare, Mortsel, Belgium) of the main study center (name of the university hospital blinded for review).

\section{Image analysis}

Image analysis was performed by a radiologist (R1, initials - blinded for review) with five years of experience in spinal MRI. In addition, intra- and inter-reader agreement was systematically assessed. To determine the intra-reader agreement, image analysis of $25 \%$ of randomly selected cases ( $n=25$ patients equal $125 \mathrm{seg}$ ments) was repeated by R1 (after a time interval of four weeks to avoid recall bias). To determine the inter-reader agreement, a second radiologist (R2, initials - blinded for review) with seven years of experience in spinal MRI additionally analyzed the same previously selected subset of $25 \%$ of the cases. Both radiologists evaluated the images in two steps. First, all sagittal T1w and T2w images were evaluated. Fat-suppressed fluid-sensitive sequences or other imaging planes were, however, not shown to the readers during the first step. Second, after a time interval of four weeks, only the sagittal fat-suppressed fluid-sensitive MRI sequences were analyzed. During the second step, readers were blinded to all other sequences. Images were shown randomly and both readers were always blinded to the patient data.

The presence or absence (yes/no) and type of Modic end-plate changes (Modic I, II and III) were evaluated according to the Modic classification [5]. Minute spots ( $<2 \mathrm{~mm}$ ) of signal intensity changes in the bone marrow contiguous to the vertebral corners were not noted. The detailed per segment image analysis was adapted from Arana et al. [25]: We recorded the presence of predominant and if present non-dominant Modic changes and the location of Modic I changes was recorded (upper, lower or both vertebral end-plates of a segment). Furthermore, the extent of Modic I changes was recorded ( $\triangleright$ Fig. 3 ) using a 3 - and 4-point Likert scale, respectively: the maximum height (craniocaudally) affected by Modic changes ( 1 , only the end-plate; $2,<25 \%$ of the vertebral body; 3 , between $25 \%$ and $50 \%$ of the vertebral body; $4,>50 \%$ of the vertebral body), the maximum volume of Modic changes in relation to the entire vertebral body (1, only the end-plate; 2 , $<25 \%$ of the vertebral body; 3 , between $25 \%$ and $50 \%$ of the vertebral body; $4,>50 \%$ of the vertebral body), and the end-plate extension of Modic changes in the anteroposterior direction ( $1,<25 \%$ of the end-plate; 2 , between $25 \%$ and $50 \%$ of the end-plate; $3,>50 \%$ of the end-plate). Detection of Modic I changes was considered positive if predominant or non-dominant Modic I changes were found. Furthermore, based on the image analysis described above, a patient-based analysis was performed in the same manner.

\section{Error analysis/consensus reading}

To assess possible errors during image analysis, both readers then mutually reviewed all cases that showed discrepancy between Modic I changes detected using T1w/T2w versus fat-suppressed fluid-sensitive sequences. Two possible scenarios were evaluated: first, Modic I changes were seen on fat-suppressed fluid-sensitive sequences but not on T1w/T2w sequences. Second, Modic I changes were seen on T1w/T2w but not on fat-suppressed fluidsensitive sequences. For this error analysis, T1w, T2w and fat-suppressed fluid-sensitive sequences were displayed in a non-blinded 
fashion simultaneously on a screen and both readers decided in consensus whether the Modic I changes were actually detectable in T1w and T2w, and fat-suppressed fluid-sensitive sequences (yes/no):

\section{Statistical analysis}

Categorical variables were expressed as frequencies and percentages; continuous variables were expressed as mean \pm standard deviation (range). Testing for normality was performed using the Shapiro-Wilk test. The Cohen $k$ test was performed to assess the inter- and intra-reader agreement. According to the method of Landis and Koch [26], k values of $0.61-0.80$ indicated substantial agreement, and values of $0.81-1.00$ indicated excellent agreement. The McNemar test was used to determine the statistical significance of differences among T1w/T2w and fat-suppressed fluid-sensitive sequences for the detection of Modic changes on a per patient and per segment basis. The Wilcoxon signed rank test was used to assess pairwise differences in the extension of Modic I changes among T1w/T2w sequences and fat-suppressed fluid-sensitive MRI sequences. The Mann-Whitney $U$ test was used to assess differences among the extension of Modic I changes in fat-suppressed fluid-sensitive sequences in segments which were evaluated as positive in T1w/T2w. Cramer's V correlation coefficient test was conducted to assess associations between the dominant presence of Modic II changes and missed Modic I changes in T1w/T2w sequences to investigate whether fatty Modic II changes possibly impede the detection of Modic I changes.

A p-value of $<0.05$ was considered statistically significant. All statistical calculations were performed using commercially available software (IBM SPSS Statistics, Version 21.0.: IBM Corp. Armonk, NY, USA).

\section{Results}

\section{Inter- and intra-reader agreement}

The inter-reader agreement regarding the presence of Modic I end-plate changes was excellent in $\mathrm{T} 1 \mathrm{w} / \mathrm{T} 2 \mathrm{w}$ sequences $(k=0.807, p<0.001)$ and substantial in fat-suppressed fluid-sensitive MRI sequences $(k=0.736, p<0.001)$. The inter-reader agreement regarding the predominant and non-dominant type of Modic changes was substantial $(k=0.686, p<0.001)$ and was excellent $(k=0.804, p<0.001)$ regarding the extension of Modic I changes in the vertebral body.

Intra-reader agreement calculations demonstrated excellent agreement regarding the presence $(\mathrm{T} 1 \mathrm{w} / \mathrm{T} 2 \mathrm{w}$ : $k=0.870$, $\mathrm{p}<0.001$; fat-suppressed fluid-sensitive: $\mathrm{k}=0.862, \mathrm{p}<0.001)$ and extension (height, volume, and anteroposterior end-plate extension; $k=0.852, p<0.001)$ of Modic changes and substantial agreement $(k=0.723, p<0.001)$ regarding the predominance of Modic changes.

\section{Modic changes in $\mathrm{T} 1 \mathrm{w} / \mathrm{T} 2 \mathrm{w}$ sequences}

In $93 / 100$ patients (93\%) or in $274 / 500$ vertebral segments (55\%), Modic changes (either type I, II or III) were detected by
T1w/T2w sequences. The majority of predominant end-plate changes were Modic II changes in 206/274 segments (75\%), followed by Modic I changes in 39/274 segments (14\%), and Modic III changes in 29/274 segments (11\%). In addition to the predominant Modic changes, non-dominant Modic changes were also detected in 123/500 (25\%) segments, with Modic I changes in $54 / 123$ segments (44\%), Modic II changes in 44/123 segments (36\%), and Modic III changes in 25/123 segments (20\%).

\section{Modic I changes in fat-suppressed fluid-sensitive sequences and comparison to $\mathrm{T} 1 \mathrm{w} / \mathrm{T} 2 \mathrm{w}$ sequences}

Modic I changes were found significantly $(p<0.001)$ more often in fat-suppressed fluid-sensitive MRI sequences (in 74/100 (74\%) patients with a total of 156/500 (31\%) vertebral segments) compared to $\mathrm{T} 1 \mathrm{w} / \mathrm{T} 2 \mathrm{w}$ imaging (in 54/100 (54\%) patients with a total of $93 / 500$ (19\%) segments).

This results in an additional 20 patients with a total of 63 additional segments detected with Modic I changes by use of fat-suppressed fluid-sensitive sequences compared to use of T1w/T2w images only ( $\triangleright$ Fig. 4 ).

\section{Location and extension of Modic I changes}

Based on fat-suppressed fluid-sensitive MRI sequences, most Modic I changes were found to be located at level L4/5 (38/156, $24 \%)$, followed by L3/4 ( $n=34 / 156,22 \%), L 2 / 3(n=32 / 156$, $21 \%), L 5 / S 1$ ( $n=31 / 15620 \%)$, and L1/2 ( $n=21 / 156,13 \%)$.

The results of the extension of Modic I changes, particularly in regard to the height, volume, and anteroposterior end-plate extension, detected on T1w/T2w- and fat-suppressed fluid-sensitive sequences are summarized in $>$ Table 1, $>$ Fig. 5 . These three extension parameters of Modic I changes, which were only detected in fat-suppressed fluid-sensitive sequences were significantly smaller compared to Modic I changes which were detected in both $\mathrm{T} 1 \mathrm{w} / \mathrm{T} 2 \mathrm{w}$ and fat-suppressed fluid-sensitive sequences: mean height: $1.8 \pm 0.8$ and $2.54 \pm 0.8$, respectively, $\mathrm{p}<0.001$; mean volume: $1.72 \pm 0.7$ and $2.34 \pm 0.8$, respectively, $p<0.001$; mean end-plate extension $1.97 \pm 0.9$ and $2.46 \pm 0.8$, respectively, $\mathrm{p}<0.01$.

\section{Error analysis/consensus reading}

The error analysis revealed that in two segments in which Modic I changes were described in $\mathrm{T} 1 \mathrm{w} / \mathrm{T} 2 \mathrm{w}$ sequences no correlate in fatsuppressed fluid-sensitive sequences was found.

In 31 (49\%) of the 63 additional vertebral segments that were initially missed in the $T 1 \mathrm{w} / \mathrm{T} 2 \mathrm{w}$ sequences but which were detected by fat-suppressed fluid-sensitive sequences, the Modic I changes were retrospectively visible during the unblinded error analysis in T1w/T2w sequences. In 32 (51\%) of the 63 segments, the Modic I changes detected in fat-suppressed fluid-sensitive sequences were even retrospectively not visible in $T 1 w / T 2 w$ sequences, even when both types of sequences (T1w/T2w and fat-suppressed fluid-sensitive sequences) were analyzed next to each other. According to the original definition of Modic et al., these findings correspond to Modic 1 changes.

In 41 (65\%) of these 63 missed vertebral segments with Modic I changes, dominant Modic II changes were present with a signifi- 

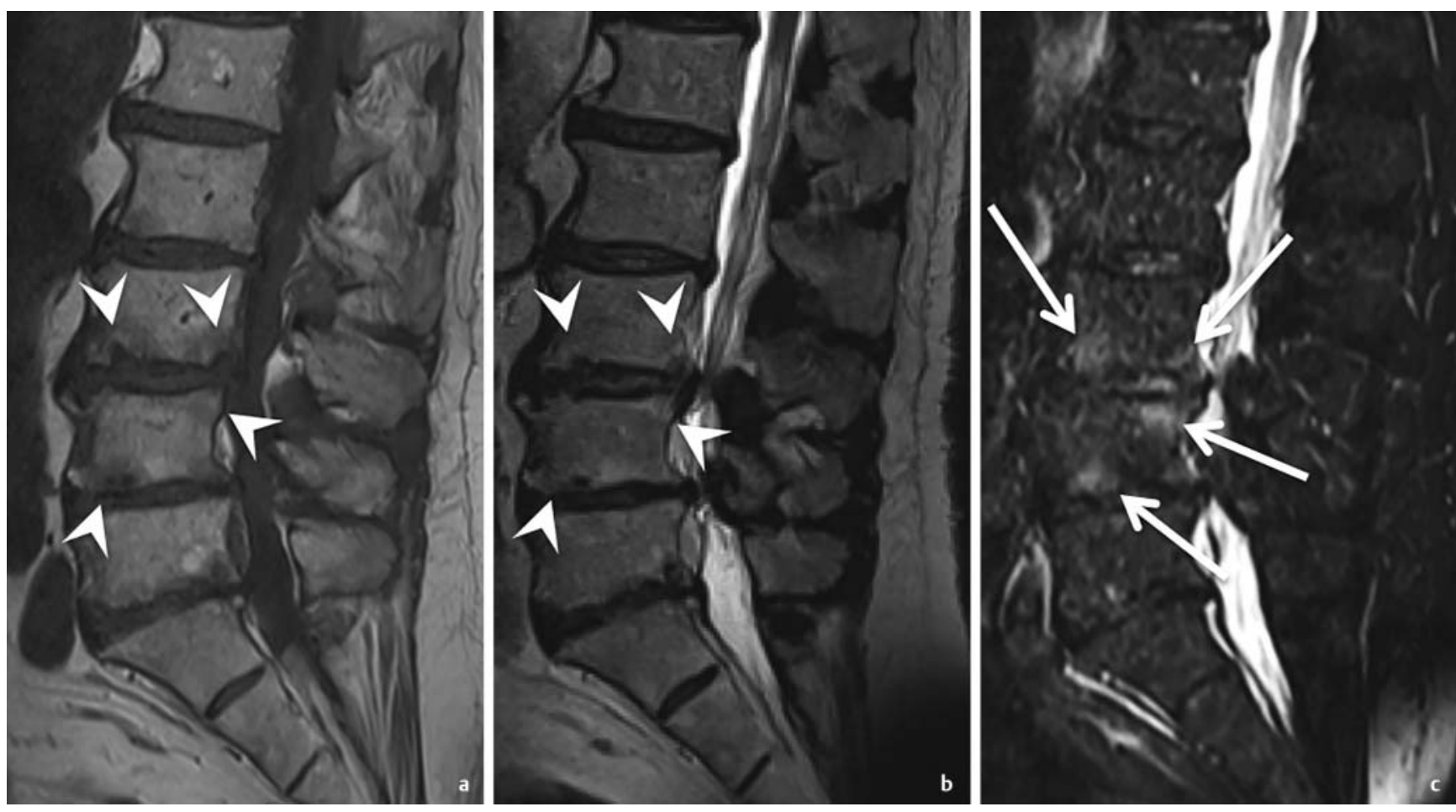

- Fig. 4 Sagittal MRI sequences of a 70-year-old female patient with Modic I changes involving both facing vertebra of segment L3/4 that are clearly visible as a hyperintensity on SPIR sequence (arrows, c), but almost not visible on T1w a and T2w images $\mathbf{b}$. Subtle hypointense bone marrow changes become barely visible on the T1w a sequence when compared to the hyperintensity of the SPIR sequence $\mathbf{c}$.

- Abb. 4 Sagittale MRT-Sequenzen einer 70-jährigen Patientin mit Modic-1-Veränderungen, die beide gegenüberliegenden Wirbelkörper des Segments L3/4 involvieren und deutlich als Hyperintensität auf der SPIR-Sequenz sichtbar sind (Pfeile, c), jedoch auf den Standard T1- a und T2b Sequenzen kaum abgrenzbar sind. Lediglich andeutungsweise werden Hypointensitäten auf der Standard T1- a Sequenz sichtbar, wenn diese mit den Hyperintensitäten auf der SPIR-Sequenz c verglichen werden.

cant correlation between the presence of Modic II and the fact of missing Modic I changes in T1w/T2w imaging (Cramer's V = 0.167, $\mathrm{p}<0.05)(\triangleright$ Fig. 6).

The mean extension of Modic I changes that were only visible in fat-suppressed fluid-sensitive sequences and even retrospectively were not visible on $\mathrm{T} 1 \mathrm{w} / \mathrm{T} 2 \mathrm{w}$ sequences were comparatively small: $1.65 \pm 0.7$ (Modic I height extension), $1.62 \pm 0.7$ (Modic I volume extension) and $2.0 \pm 0.9$ (Modic I end-plate extension).

\section{Discussion}

In 1988, when Modic et al. defined the Modic classification according to T1w/T2w sequences, the standard T2w sequences applied on older scanners were heavily T2-weighted with consequent suppression of large amounts of fat signal ( $\triangleright$ Fig. 1) [5]. This resulted in good visibility of bright, edema-like changes within the suppressed dark adjacent fat; one might say that the formerly used standard T2w sequences were virtually fat-suppressed. Nowadays, standard T2w sequences are usually not edemasensitive, because the bright fat signal masks edema-like changes. Thus, the way Modic changes were defined historically is no longer fully applicable. However, the detection of Modic I changes is clinically relevant since they are associated with pain [3, 7-12, $14,15]$ and intra- or peridiscal injections might be a therapeutic

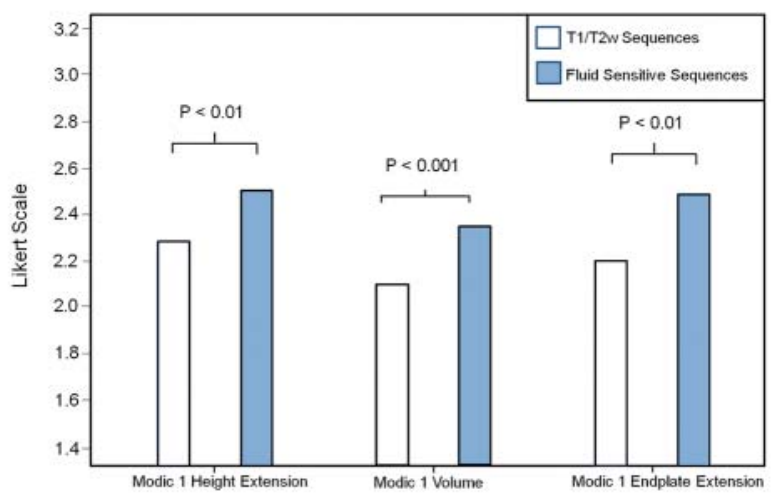

- Fig. 5 Pairwise comparison of the extension (height, volume, and end-plate extension) of Modic I changes among T1w/T2w and fatsuppressed fluid-sensitive MRI sequences. Note the significantly larger extension of Modic I changes found on fat-suppressed fluidsensitive sequences compared to T1w/T2w imaging.

- Abb. 5 Gegenüberstellung der Ergebnisse für die Evaluation von Modic-1-Veränderungen mittels Standard T1-/T2- und flüssigkeitssenitiven Sequenzen anhand der drei Ausdehnungsparameter: maximal betroffene Höhe (kraniokaudal), maximale betroffenes Volumen sowie maximale Endplattenausdehnung in anteroposteriorer Ausdehnung. 
- Table 1 - Frequencies and characteristics of Modic I changes in T1w/T2w and fat-suppressed fluid-sensitive MRI sequences.

- Tab. 1 Häufigkeiten und Verteilungsmuster von Modic-1-Veränderungen in T1/T2 und fettgesättigten, flüssigkeitssensitiven MRT-Sequenzen.

\begin{tabular}{|c|c|c|}
\hline & $\mathrm{T} 1 \mathrm{w} / \mathrm{T} 2 \mathrm{w}$ sequences & fat-suppressed fluid-sensitive sequences \\
\hline number of modic I changes/maximum number of segments & $93 / 500$ & $156 / 500$ \\
\hline \multicolumn{3}{|l|}{ location at end-plates } \\
\hline - upper end-plate & $13(14 \%)$ & $29(19 \%)$ \\
\hline - lower end-plate & $9(9.7 \%)$ & $24(15 \%)$ \\
\hline - both & $71(76 \%)$ & $103(66 \%)$ \\
\hline \multicolumn{3}{|l|}{ Max. height of vertebral body affected } \\
\hline - only end-plate & $12(13 \%)$ & $30(19 \%)$ \\
\hline - $<25 \%$ & $53(57 \%)$ & $76(49 \%)$ \\
\hline - $25-50 \%$ & $20(22 \%)$ & $35(22 \%)$ \\
\hline.$>75 \%$ & $8(9 \%)$ & $15(10 \%)$ \\
\hline - mean likert score \pm SD & $2.27 \pm 0.79$ & $2.53 \pm 0.82$ \\
\hline \multicolumn{3}{|l|}{ Max. volume of vertebral body affected } \\
\hline - only end-plate & $12(13 \%)$ & $30(19 \%)$ \\
\hline - $<25 \%$ & $65(70 \%)$ & $94(60 \%)$ \\
\hline - $25-50 \%$ & $12(13 \%)$ & $20(13 \%)$ \\
\hline . $>75 \%$ & $4(4 \%)$ & $12(8 \%)$ \\
\hline - mean likert score \pm SD & $2.1 \pm 0.65$ & $2.35 \pm 0.76$ \\
\hline \multicolumn{3}{|l|}{ Max. end-plate extension } \\
\hline - $<25 \%$ & $23(25 \%)$ & $43(28 \%)$ \\
\hline . $25-50 \%$ & $32(34 \%)$ & $30(19 \%)$ \\
\hline . $>50 \%$ & $38(41 \%)$ & $83(53 \%)$ \\
\hline - mean likert score \pm SD & $2.19 \pm 0.81$ & $2.46 \pm 0.76$ \\
\hline
\end{tabular}

option for selected patients [27, 28]. Surprisingly, and to the best of our knowledge, there is no prior literature regarding a systematic analysis of fat-suppressed fluid-sensitive MRI sequences for the detection and characterization of vertebral end-plate changes. A premise of our study is that an increased fluid signal on fat-suppressed fluid-sensitive sequences equates to Modic I changes. Inherently, we have no invasive histopathologic proof.

According to our study, Modic I end-plate changes were detected more frequently and with a greater extent using fat-suppressed fluid-sensitive MRI sequences at lumbar spine MRI compared to standard T1w/T2w sequences. Fat-suppressed fluid-sensitive MRI sequences detected smaller Modic I changes more often compared to T1w/T2w sequences. In $20 \%$ of our patients, at least one segment with Modic I changes would have been missed if no fat-suppressed fluid-sensitive MRI sequences had been available. As stated before, there is no literature to compare our results. We only found one small case report series on four golf players, reported by Mefford et al., that mentioned only marginally the role of short tau inversion recovery (STIR) sequences for the diagnosis of Modic I changes [29].
The observed added value of fat-suppressed fluid-sensitive sequences in our study is likely caused by the increased contrast due to fat-suppression and the resulting higher conspicuity of the typical edema-like appearance of Modic I changes on MRI within an otherwise relatively hypointense vertebral body. This hypothesis is supported by our observation of improved detection of Modic I changes by fat-suppressed fluid-sensitive sequences in the presence of distinct adjacent fat-like Modic II changes. Evidently, these adjacent T1w/T2w hyperintense fatty bone marrow changes made the additional T2w hyperintense signal caused by edema-like bone marrow changes more difficult to detect on standard $\mathrm{T} 1 \mathrm{w} / \mathrm{T} 2 \mathrm{w}$ sequences.

The error analysis and the consensus reading demonstrated that some Modic I changes, visible on fat-suppressed fluid-sensitive MRI sequences, could not be seen even retrospectively on standard T1w/T2w sequences. These findings seemed to us rather as a less distinct form of Modic I changes than one of the wellknown artifacts of fat-suppressed fluid-sensitive sequences [30]. This is in line with the classification of Fredericson et al. that assigned the medial tibial stress syndrome to a higher grade if 

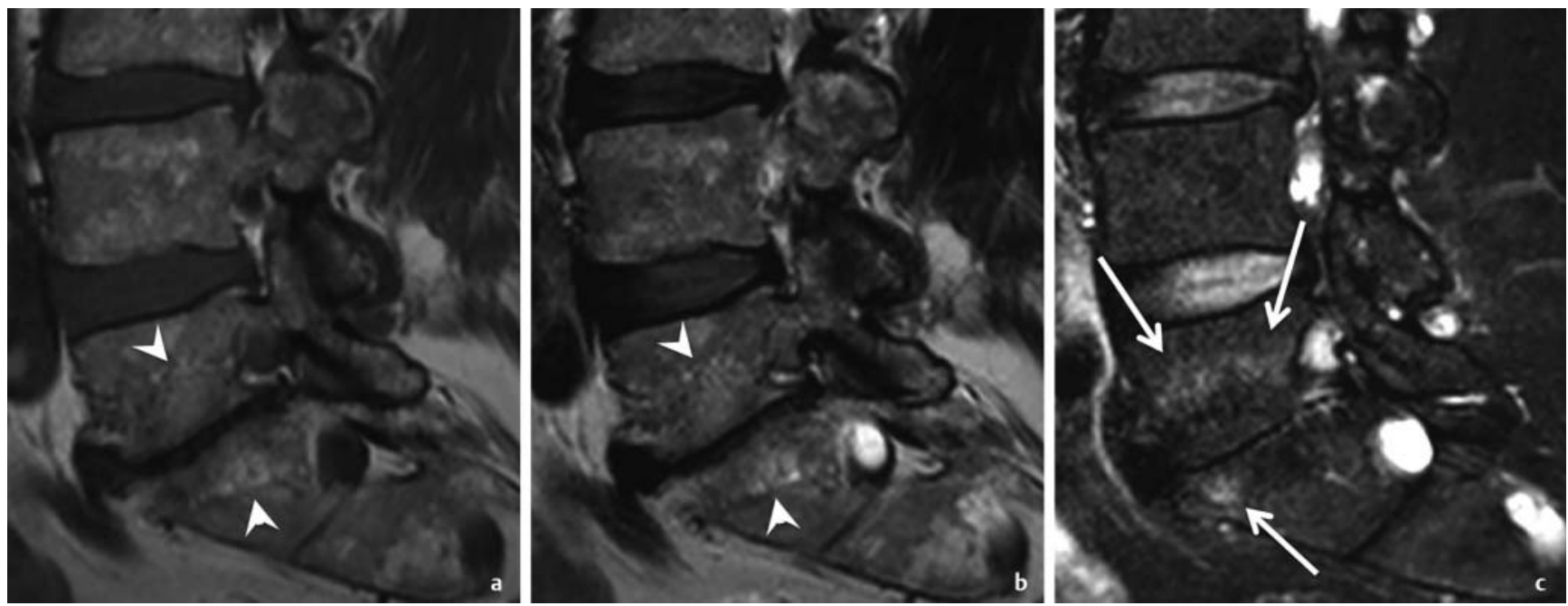

- Fig. 6 Sagittal MRI sequences of a 67-year-old male patient illustrate a case where no Modic I changes were seen on T1w a and T2w images b, but moderate Modic I changes involving both end-plates of segment L5 / S1 were visible on the SPAIR sequence (arrows) c. There were some hyperintense fat-like Modic II end-plate changes (arrowheads) visible on standard T1w/T2w sequences that may mask the Modic I changes.

- Abb. 6 Sagittale MRT-Sequenzen eines 67-jährigen männlichen Patienten illustrieren einen Fall, in dem auf den Standard T1- a und T2- b Sequenzen keine Modic-1-Veränderungen sichtbar sind, aber moderate Modic-1-Veränderungen, die beide Endplatten des Segments L5 / S1 involvieren, auf den SPIR-Sequenzen (Pfeile) c abgrenzbar sind. Einige angrenzende hyperintense fettige Modic-2-Veränderungen (Pfeilspitzen) sind auf den Standard T1-/T2-Sequenzen sichtbar, die möglicherweise den Nachweis der Modic-1-Veränderungen maskieren.

bone marrow edema was seen not only on T2w but also on both T1w and T2w sequences [31]. All of these changes were, however, relatively small and one might question - based on Jarvinen et al. [9] who showed that the size of Modic I changes is positively correlated with pain - the relevance of these subtle findings, while Weishaupt et al. used provocative discography as the reference standard to show that even slight Modic I changes are associated with pain [10]. Nevertheless, all of these Modic I changes would have definitively been missed without the use of fat-suppressed fluid-sensitive MRI sequences. It might be reasonable to introduce a new or an adapted definition of Modic I changes in light of the fundamentally different characteristics of the T2w sequences used back in 1988 and nowadays. A high signal on fat-suppressed fluid-sensitive sequences without hypointensity on T1w sequences could be referred to as moderate Modic I changes, whereas a high signal on fat-suppressed fluid-sensitive sequences with corresponding hypointensity on T1w sequences could be referred to as distinct Modic I changes. Certainly, further research is needed to prove this concept.

Our study has limitations. First, the patients selected for this study were all suspected of having lumbar spinal canal stenosis. Thus, there might be a selection bias. However, this is likely irrelevant for our study with the scope to assess the detection performance of Modic I changes. Second, in our study different fat suppression techniques were used and overall considered as "fatsuppressed fluid-sensitive" sequences. We did not perform a sub-analysis to determine whether one fat-suppression technique works better than others since in the clinical routine we read and evaluate images from different sites, scanners and fat suppression techniques. Third, we decided to compare standard T1w/T2w sequences, as used in the definition of Modic et al., against fat- suppressed fluid-sensitive MRI sequences alone. Commonly, in everyday clinical work the fat-suppressed fluid-sensitive MRI sequence only is analyzed for Modic 1 detection and not in a combination with T1w sequences. Furthermore, we do not believe that the addition of T1w sequences to fat-suppressed fluid-sensitive sequences would notably influence the detection of Modic 1 changes. Last, as stated before we have no invasive histopathologic proof that a high vertebra bone marrow signal adjacent to the end-plates in fat-suppressed fluid-sensitive sequences equates to Modic I changes. However, in the clinical routine they are often treated equally.

In conclusion, fluid-sensitive MRI sequences of the lumbar spine revealed significantly more Modic I end-plate changes and demonstrated a greater extent compared to standard T1w/T2w imaging and thus should constitute an integral part of routine lumbar spine MRI protocols.

\section{CLINICAL RELEVANCE}

- Modic I changes are strongly associated with pain and thus their detection is important

- Fat-suppressed fluid-sensitive MRI sequences revealed more and a greater extent of Modic I changes

Conflict of Interest

The authors declare that they have no conflict of interest. 


\section{References}

[1] Gallucci M, Puglielli E, Splendiani A et al. Degenerative disorders of the spine. Eur Radiol 2005; 15: 591 - 598

[2] Brant-Zawadzki MN, Dennis SC, Gade GF et al. Low back pain. Radiology 2000; 217: $321-330$

[3] Arnbak B, Jensen TS, Egund N et al. Prevalence of degenerative and spondyloarthritis-related magnetic resonance imaging findings in the spine and sacroiliac joints in patients with persistent low back pain. Eur Radiol 2016; 26: $1191-1203$

[4] Airaksinen O, Brox JI, Cedraschi C et al. Chapter 4. European guidelines for the management of chronic nonspecific low back pain. Eur Spine J 2006; 15 (Suppl. 2): S192-S300

[5] Modic MT, Steinberg PM, Ross JS et al. Degenerative disk disease: assessment of changes in vertebral body marrow with MR imaging. Radiology 1988; 166: 193-199

[6] Jevtic V. Magnetic resonance imaging appearances of different discovertebral lesions. Eur Radiol 2001; 11: 1123-1135

[7] Jensen TS, Karppinen J, Sorensen JS et al. Vertebral endplate signal changes (Modic change): a systematic literature review of prevalence and association with non-specific low back pain. Eur Spine J 2008; 17: $1407-1422$

[8] Albert HB, Kjaer P, Jensen TS et al. Modic changes, possible causes and relation to low back pain. Med Hypotheses 2008; 70: 361-368

[9] Jarvinen J, Karppinen J, Niinimaki J et al. Association between changes in lumbar Modic changes and low back symptoms over a two-year period. BMC Musculoskelet Disord 2015; 16: 98

[10] Weishaupt D, Zanetti M, Hodler J et al. Painful Lumbar Disk Derangement: Relevance of Endplate Abnormalities at MR Imaging. Radiology 2001; 218: $420-427$

[11] Mitra D, Cassar-Pullicino VN, McCall IW. Longitudinal study of vertebral type-1 end-plate changes on MR of the lumbar spine. Eur Radiol 2004; 14: $1574-1581$

[12] Kjaer P, Korsholm L, Bendix T et al. Modic changes and their associations with clinical findings. Eur Spine J 2006; 15: 1312-1319

[13] Liphofer JP, Theodoridis T, Becker GT et al. (Modic) signal alterations of vertebral endplates and their correlation to a minimally invasive treatment of lumbar disc herniation using epidural injections. RoFo : Fortschritte auf dem Gebiete der Rontgenstrahlen und der Nuklearmedizin 2006; 178: 1105-1114

[14] Kuisma M, Karppinen J, Niinimaki J et al. Modic changes in endplates of lumbar vertebral bodies: prevalence and association with low back and sciatic pain among middle-aged male workers. Spine (Phila Pa 1976) 2007; 32: $1116-1122$

[15] Toyone T, Takahashi K, Kitahara $\mathrm{H}$ et al. Vertebral bone-marrow changes in degenerative lumbar disc disease: An MRI study of 74 patients with low back pain. J Bone Joint Surg Br 1994; 76: 757-764
[16] Dudli S, Fields A], Samartzis D et al. Pathobiology of Modic changes. Eur Spine J 2016; 25: 3723-3734

[17] Albert HB, Manniche C. Modic changes following lumbar disc herniation. Eur Spine J 2007; 16: 977-982

[18] Perilli E, Parkinson IH, Truong LH et al. Modic (endplate) changes in the lumbar spine: bone micro-architecture and remodelling. Eur Spine J 2015; 24: 1926 - 1934

[19] Farshad-Amacker NA, Hughes A, Herzog RJ et al. The intervertebral disc, the endplates and the vertebral bone marrow as a unit in the process of degeneration. Eur Radiol 2017; 27: 2507-2520

[20] Becker GT, Willburger RE, Liphofer J et al. Distribution of MRI signal alterations of the cartilage endplate in pre-operated patients with special focus on recurrent lumbar disc herniation. RoFo : Fortschritte auf dem Gebiete der Rontgenstrahlen und der Nuklearmedizin 2006; 178: $46-54$

[21] Albert HB, Lambert P, Rollason J et al. Does nuclear tissue infected with bacteria following disc herniations lead to Modic changes in the adjacent vertebrae? Eur Spine J 2013; 22: 690-696

[22] Albert HB, Sorensen JS, Christensen BS et al. Antibiotic treatment in patients with chronic low back pain and vertebral bone edema (Modic type 1 changes): a double-blind randomized clinical controlled trial of efficacy. Eur Spine J 2013; 22: 697-707

[23] Patel ND, Broderick DF, Burns J et al. ACR Appropriateness Criteria Low Back Pain. J Am Coll Radiol 2016; 13: 1069-1078

[24] Steurer J, Nydegger A, Held U et al. LumbSten: the lumbar spinal stenosis outcome study. BMC Musculoskelet Disord 2010; 11: 254

[25] Arana E, Royuela A, Kovacs FM et al. Lumbar spine: agreement in the interpretation of 1.5-T MR images by using the Nordic Modic Consensus Group classification form. Radiology 2010; 254: 809-817

[26] Landis JR, Koch GG. The measurement of observer agreement for categorical data. Biometrics 1977; 33: 159-174

[27] Fayad F, Lefevre-Colau MM, Rannou F et al. Relation of inflammatory modic changes to intradiscal steroid injection outcome in chronic low back pain. Eur Spine J 2007; 16: 925 - 931

[28] Cao P, jiang L, Zhuang $C$ et al. Intradiscal injection therapy for degenerative chronic discogenic low back pain with end plate Modic changes. Spine J 2011; 11: 100-106

[29] Mefford J, Sairyo K, Sakai T et al. Modic type I changes of the lumbar spine in golfers. Skeletal radiology 2011; 40: 467-473

[30] Delfaut EM, Beltran J, Johnson G et al. Fat suppression in MR imaging: techniques and pitfalls. Radiographics 1999; 19: 373-382

[31] Fredericson M, Bergman AG, Hoffman KL et al. Tibial stress reaction in runners. Correlation of clinical symptoms and scintigraphy with a new magnetic resonance imaging grading system. Am I Sports Med 1995; 23: $472-481$ 